University of Wollongong

Research Online

Australian Institute for Innovative Materials -

Papers

Australian Institute for Innovative Materials

$1-1-2016$

One-step synthesis of a silicon/hematite@carbon hybrid nanosheet/silicon sandwich-like composite as an anode material for Li-ion batteries

Lei Zhang

University of Wollongong, zhang@uow.edu.au

Haipeng Guo

University of Wollongong, hg476@uowmail.edu.au

Ranjusha Rajagopalan

University of Wollongong, rr876@uowmail.edu.au

Xianluo $\mathrm{Hu}$

Huazhong University of Science and Technology

Yunhui Huang

Huazhong University of Science and Technology

See next page for additional authors

Follow this and additional works at: https://ro.uow.edu.au/aiimpapers

Part of the Engineering Commons, and the Physical Sciences and Mathematics Commons

Research Online is the open access institutional repository for the University of Wollongong. For further information contact the UOW Library: research-pubs@uow.edu.au 


\title{
One-step synthesis of a silicon/hematite@carbon hybrid nanosheet/silicon sandwich-like composite as an anode material for Li-ion batteries
}

\author{
Abstract \\ Silicon and hematite, both important functional materials with high theoretical capacity, have been \\ intensively investigated separately for application as anode materials in lithium ion batteries (LIBs). The \\ main challenges associated with these anode materials are their low electronic conductivity and \\ structural degradation caused by large volume expansion during cycling, which are not tolerable for future \\ LIBs with high energy density and large power output. Active particles anchored on a porous conductive \\ skeleton are widely used for improving the electrochemical performance of silicon as well as that of \\ hematite. Herein, we develop a novel-structured carbon-silicon-hematite anode material via a single-step \\ technique that addresses these problems. In the resultant architecture, silicon nanoparticles are \\ sandwiched between the iron-oxide-embedded porous carbon sheets. The flexible and conductive carbon \\ sheets improve the conductivity and accommodate the volume changes of the embedded hematite and \\ silicon nanoparticles, and thus maintain the structural and electrical integrity. Meanwhile, the void space \\ between the carbon layers leaves enough room for the expansion and contraction of silicon during the \\ lithiation and delithiation processes. High capacity ( 1980 mA h g-1 at $750 \mathrm{~mA} \mathrm{g-1)}$ and long cycle life \\ (250 cycles) have been achieved for this sandwich-like carbon-silicon-hematite electrode.

\section{Disciplines} \\ Engineering | Physical Sciences and Mathematics

\section{Publication Details} \\ Zhang, L., Guo, H., Rajagopalan, R., Hu, X., Huang, Y., Dou, S. X. \& Liu, H. (2016). One-step synthesis of a \\ silicon/hematite@carbon hybrid nanosheet/silicon sandwich-like composite as an anode material for Li- \\ ion batteries. Journal of Materials Chemistry A, 4 (11), 4056-4061.
}

\section{Authors}

Lei Zhang, Haipeng Guo, Ranjusha Rajagopalan, Xianluo Hu, Yunhui Huang, S X. Dou, and Hua-Kun Liu 


\title{
One-Step to Synthesize Silicon/Hematite@Carbon Hybrid
}

\section{Nanosheets/Silicon Sandwich-Like Composite as Anode Materials for Li-ion Batteries}

Lei Zhang, ${ }^{a}$ Ranjusha Rajagopalan, ${ }^{a}$ Jiawei Zhang, ${ }^{a}$ Zhixin Tai, ${ }^{a}$ Jianmin Ma, ${ }^{a}$ Shixue Dou ${ }^{{ }^{*}}$ and Huakun $\operatorname{Liu}^{\mathrm{a}^{*}}$

\begin{abstract}
${ }^{a}$ Institute for Superconducting and Electronic Materials, University of Wollongong, Wollongong, NSW 2522, Australia,
\end{abstract}

*To whom correspondence should be addressed. E-mail address: hua@uow.edu.au (H. Liu), Tel.:

+61-2-4221-4547, Fax: +61-2-4221-5731. 


\begin{abstract}
Silicon and hematite, both important functional materials with high theoretical capacity, have been intensively investigated separately for their applications as anode materials in lithium ion batteries (LIBs). The main challenges associated with these anode materials are there low electronic conductivity and structural degradation caused by large volume expansion during cycling, which are not available for future LIBs with high energy density and large power output. Active particles anchored in a porous conductive skeleton are widely used for improving the electrochemical performance of silicon as well as the hematite. Herein, we develop a novel structured carbon-silicon-hematite anode via a single-step technique that tackles these problems. In the resulted architecture, silicon nanoparticles sandwiched between the iron oxide embedded porous carbon sheets. The flexible and conductive carbon sheets improve the conductivity and accommodate the volume change of the embedded silicon and hematite nanoparticles and thus maintain the structural and electrical integrity. Meanwhile, the void space between carbon layers leaves enough room for the expansion and contraction of silicon during the lithiation and delithiation process. High capacity ( 2000 $\mathrm{mAh} \mathrm{g}^{-1}$ at $\left.750 \mathrm{mAh} \mathrm{g}^{-1}\right)$ and long cycle life (200 cycles) have been achieved for this sandwich-like carbon-silicon-hematite electrode.
\end{abstract}

Keywords: Hematite; Silicon; Sandwich-like structure; Anode; Lithium ion batteries; 


\section{Introduction}

Conventional lithium ion batteries (LIBs) based on carbon anodes, such as commercial graphite microspheres and mesophase carbon microbeads (MCMB), with theoretical capacity of about 372 $\mathrm{mAh} \mathrm{g}^{-1}$, have now seen the limit of meeting the needs of high-energy storage. ${ }^{1-4}$ To meet the increasing demand for energy storage capability, novel electrode materials with higher capacity, low cost, and the ability to be produced at large scale are of great interest. ${ }^{5}$

Silicon ( $\mathrm{Si})$ and hematite $\left(\alpha-\mathrm{Fe}_{2} \mathrm{O}_{3}\right)$ have long been regarded as an appealing anode materials for LIBs because of their much higher theoretical capacities ( $\approx 4200$ and $1007 \mathrm{~mA} \mathrm{~h} \mathrm{~g}^{-1}$, respectively) than that of commercially used ones, nontoxicity and natural abundance. ${ }^{3,6-14}$ Despite of all these advantages, the full utilization of silicon or $\alpha-\mathrm{Fe}_{2} \mathrm{O}_{3}$-based batteries to date has been hindered by a series of obstacles, including the poor cycle life and rate performance, resulted from its large volumetric expansion during the cycling and low ionic/electronic conductivity. ${ }^{15-19}$ Hence, great efforts have been made to further improve their electrochemical performance by using various silicon-containing (silicon nanowires, ${ }^{10,20-21}$ silicon nanotubes, ${ }^{22}$ porous structures silicon, ${ }^{23}$ and carbon coated silicon ${ }^{24-25}$ ) or $\alpha-\mathrm{Fe}_{2} \mathrm{O}_{3}$-containing $\left(\mathrm{Fe}_{2} \mathrm{O}_{3}\right.$ nanorods, ${ }^{15} \mathrm{Fe}_{2} \mathrm{O}_{3}$ nanotubes, ${ }^{26} \mathrm{Fe}_{2} \mathrm{O}_{3}$ nanosheets, ${ }^{6}$ graphene@ $\mathrm{Fe}_{2} \mathrm{O}_{3}$ composite ${ }^{9}$ ) materials. Among them, porous carbon@Si or carbon@ $\alpha-\mathrm{Fe}_{2} \mathrm{O}_{3}$ composites in which the active particles are coated or embedded in porous conductive carbon skeleton are quite promising, because the void space allows the expansion of silicon and $\alpha-\mathrm{Fe}_{2} \mathrm{O}_{3}$ during the lithiation/ delithiation processes thus maintain the structural and electrical integrity. ${ }^{7}$ For instance, Cui et al., was demonstrated a carbon@void@Si (yolk-shell) composite system having a high capacity of $\sim 2800 \mathrm{mAh} / \mathrm{g} .{ }^{27} \alpha-\mathrm{Fe}_{2} \mathrm{O}_{3} /$ reduced graphene oxide (rGO) nanocomposites ( $1100 \mathrm{mAh} / \mathrm{g}$ ) were fabricated by Zhang et al., ${ }^{28}$ through a facile microwave hydrothermal method in which the $\alpha-\mathrm{Fe}_{2} \mathrm{O}_{3}$ nanoparticles are uniformly anchored on the graphene 
nanosheets. Therefore, the problem of silicon and $\alpha-\mathrm{Fe}_{2} \mathrm{O}_{3}$ can be tackled by combining porous structure and incorporation of carbon in one structure. To the best of our knowledge, the composite anodes explored so far contain either silicon or $\alpha-\mathrm{Fe}_{2} \mathrm{O}_{3}$ along with carbon, and no reports are available wherein both the materials are utilized in one system. It is therefore envisioned that advances in LIBs technology can be achieved by incorporating both silicon and $\alpha-\mathrm{Fe}_{2} \mathrm{O}_{3}$ in one porous carbon skeleton.

Herein, we report a facile one-step synthesis of a carbon-silicon-hematite (C-Si-Fe $\mathrm{O}_{3}$ ) composite. In our case, silicon nanoparticles (Si NPs) sandwiched between $\alpha-\mathrm{Fe}_{2} \mathrm{O}_{3}$ embedded porous carbon sheets ( $\mathrm{C} @ \mathrm{Fe}_{2} \mathrm{O}_{3}$ ). The electronic conductivity of both silicon and $\alpha-\mathrm{Fe}_{2} \mathrm{O}_{3}$ NPs can be improved by the conductive carbon layers. ${ }^{29-30}$ Meanwhile, the flexible carbon sheets are adaptable and can freely switch between the expansion and contraction of the active particles upon lithiation and delithiation. ${ }^{28,31}$ Besides, the space between the carbon layers allows the Si NPs to expand freely. ${ }^{32}$ More importantly, the $\mathrm{C} @ \mathrm{Fe}_{2} \mathrm{O}_{3}$ layers can prevent $\mathrm{Si}$ and $\alpha-\mathrm{Fe}_{2} \mathrm{O}_{3}$ nanoparticles from aggregation. These unique characteristics facilitate the collection and transport of electrons, resulting in high capacity and good cycling stability. ${ }^{33-34}$ 


\section{Experiment section}

\subsection{Material synthesis}

In this work, $0.36 \mathrm{~g}$ of iron (III) chloride hexahydrate $\left(\mathrm{FeCl}_{3} \cdot 6 \mathrm{H}_{2} \mathrm{O}, 1.33 \mathrm{mmol}\right.$, Sigma-Aldrich, 98\%) was dissolved in $1.22 \mathrm{~g}$ of oleic acid (Sigma-Aldrich). The resulting mixture was aged at $85^{\circ} \mathrm{C}$ for $3 \mathrm{~h}$, and then mixed with $600 \mathrm{mg}$ Si $(\sim 100 \mathrm{~nm})$. The mixture was heated to $600{ }^{\circ} \mathrm{C}$ at the heating rate of $5{ }^{\circ} \mathrm{C} \min ^{-1}$ under $\mathrm{Ar}$ atmosphere for $3 \mathrm{~h}$ and then washed with distilled water to get the final material (C-Si-Fe $\mathrm{O}_{3}$ ). For the comparison, carbon coated silicon (C-Si) composite was fabricated for which $600 \mathrm{mg} \mathrm{Si}$ was mixed with $1.22 \mathrm{~g}$ of oleic acid. Then, the mixture was heated to $600{ }^{\circ} \mathrm{C}$ at the heating rate of $5{ }^{\circ} \mathrm{C} \mathrm{min}^{-1}$ under $\mathrm{Ar}$ atmosphere for $3 \mathrm{~h}$ to get $\mathrm{C}$-Si.

\subsection{Characterization}

The products, C-Si- $\mathrm{Fe}_{2} \mathrm{O}_{3}$, C-Si and Si NPs, were analyzed by X-ray diffraction (XRD; GBC MMA) with $\mathrm{Cu}$ Ka radiation; Raman spectroscopy (JobinYvon HR800) employing a $10 \mathrm{~mW}$ helium/neon laser at $632.8 \mathrm{~nm}$; field emission scanning electron microscopy (FESEM; JEOL 7500) and transmission electron microscopy (TEM; JEOL ARM-200F) with high-resolution TEM (HRTEM). Elemental CHN (Carbon-Hydrogen-Nitrogen mode) analysis was conducted for determining the carbon content in C-Si-Fe $\mathrm{O}_{3}$. The X-ray photoelectron spectra (XPS) experiment was carried out using Al K-alpha radiation and fixed analyser transmission mode. The pass energy was $60 \mathrm{eV}$ for the survey spectra and $20 \mathrm{eV}$ for specific elements.

\subsection{Electrochemical measurement}

The tests were conducted by assembling coin-type half cells in an argon-filled glove box. Lithium foil was employed as both reference and counter electrode. The working electrode consisted of 70 
wt.\% active material (C-Si-Fe $\mathrm{O}_{3}$, C-Si and Si NPs, respectively), 20 wt.\% carbon black, and 10 wt.\% carboxymethyl cellulose (CMC) binder. The electrolyte was $1.0 \mathrm{M} \mathrm{LiPF}_{6}$ in a 1:1 (v/v) mixture of ethylene carbonate (EC) and diethyl carbonate (DEC). Electrochemical cycling of coin cells was conducted at $750 \mathrm{~mA} \mathrm{~g}^{-1}$ using galvanostatic mode in the potential window of $10 \mathrm{mV}$ to $2.8 \mathrm{~V}$ (vs. $\mathrm{Li} / \mathrm{Li}^{+}$). Cyclic voltammetry was performed using a Biologic VMP-3 electrochemical workstation between 0.01 and $2.8 \mathrm{~V}$ at a scan rate of $0.1 \mathrm{mV} \mathrm{s}^{-1}$.

\section{Results and discussion}

Fig. S1 shows a typical SEM image of Si NPs, which are in the size range of around $100 \mathrm{~nm}$. The obtained C-Si composite in Fig. 1a exhibits an interconnected network, forming a continuous three dimensional (3D) structure. The higher magnification image of C-Si (Fig. 1b) shows that Si NPs were well connected with each other through the carbon coating layers. Compared with C-Si, $\mathrm{C}-\mathrm{Si}-\mathrm{Fe}_{2} \mathrm{O}_{3}$ (Fig. 1c) shows a significantly different structure. It can be seen, C-Si-Fe ${ }_{2} \mathrm{O}_{3}$ possesses a layer-by-layer assembled structure. Si NPs are dispersed between the $\mathrm{Fe}_{2} \mathrm{O}_{3}$ embedded carbon $\left(\mathrm{C} @ \mathrm{Fe}_{2} \mathrm{O}_{3}\right.$ ) layer and these $\mathrm{C} @ \mathrm{Fe}_{2} \mathrm{O}_{3}$ layers prevent the aggregation of $\mathrm{Si}$ NPs and $\alpha-\mathrm{Fe}_{2} \mathrm{O}_{3}$ nanoparticles during the annealing process. More importantly, portions of carbon sheets stacked reconstitute to form a porous conductive network, and this unique interconnected 3D nanostructure not only improves the electronic conductivity, but also provides void space to accommodate the volume change of Si NPs and $\alpha-\mathrm{Fe}_{2} \mathrm{O}_{3}$ during cycling while maintaining the mechanical stability. ${ }^{32}$ Fig. 1d shows the enlarged image of $\mathrm{C} @ \mathrm{Fe}_{2} \mathrm{O}_{3}$ layer, where uniformly embedded $\alpha-\mathrm{Fe}_{2} \mathrm{O}_{3} \mathrm{NPs}$ in the size range of 30-40 nm were clearly seen on the carbon layers. 


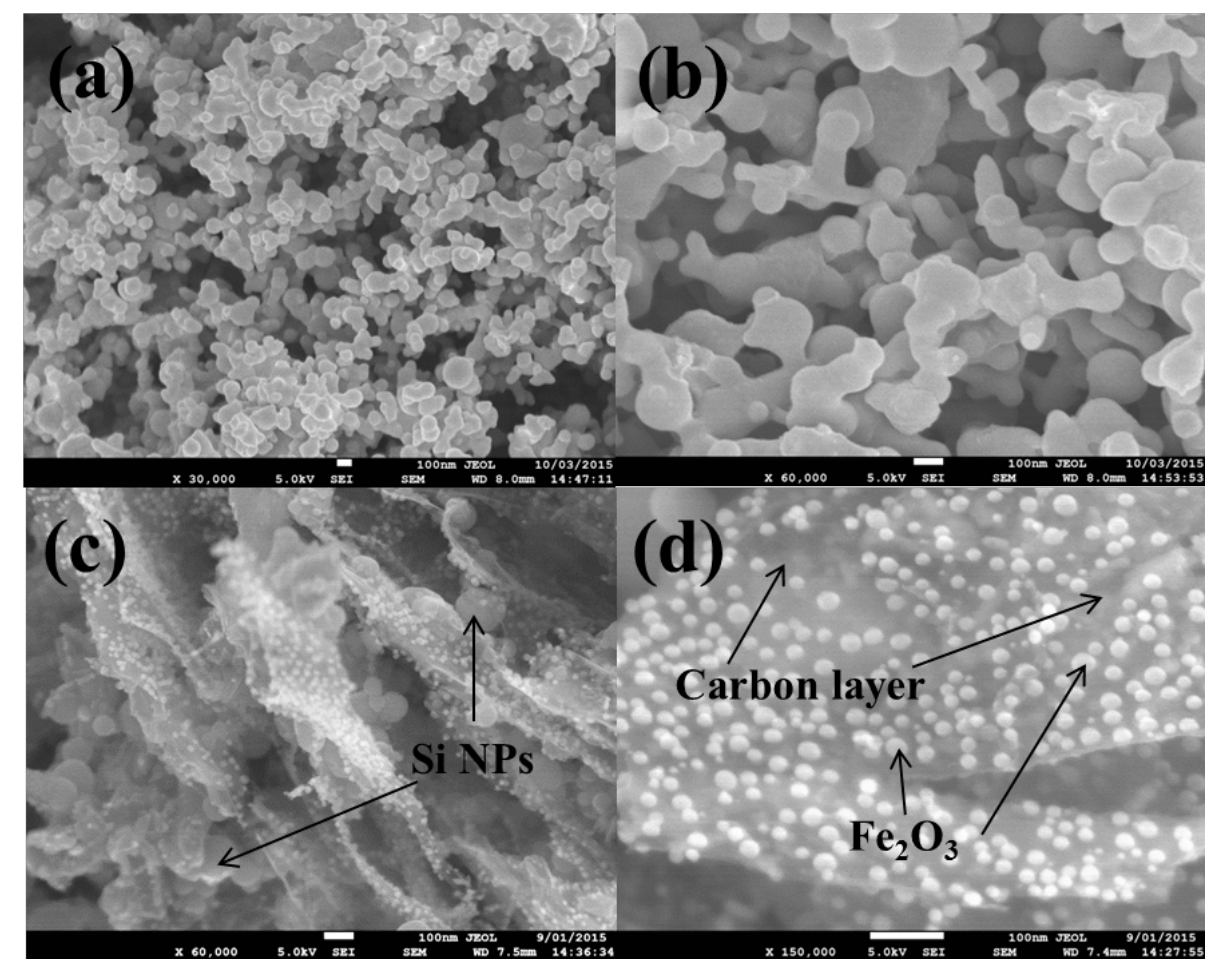

Fig. 1. SEM images of C-Si (a and b), and C-Si-Fe $\mathrm{O}_{3}$ (c and d)

The energy dispersive X-ray (EDX) data in Fig. S2a shows that only carbon and silicon can be found in this sample (Cu peaks arise from the specimen holder). Fig. S2b shows the TEM image of C-Si. It can be seen, C-Si is composed of carbon coated Si NPs in a size range of 80-130 nm and all of these particles are interconnected with surface coated amorphous carbon (AC) stemmed from oleic acid. The enlarged TEM image of C-Si (Fig. 2Sc) shows that the thickness of the carbon coating layer on the silicon surface is around 10-15 nm. The carbon (Fig. 2Sd) and silicon (Fig. 2Se) elemental mapping images indicate that the Si NPs are homogenously coated with the interconnected carbon coating layer and every single silicon nanoparticle is separated from each other due to the outer carbon shell (please see Fig. 2Sf). Fig. 2a shows that carbon, silicon and iron can be found in $\mathrm{C}-\mathrm{Si}-\mathrm{Fe}_{2} \mathrm{O}_{3}$. The elements mapping images (Fig. 2c to 2f) show that, even after the ultrasonication used to disperse the $\mathrm{C}-\mathrm{Si}-\mathrm{Fe}_{2} \mathrm{O}_{3}$ composite for TEM characterization, $\alpha-\mathrm{Fe}_{2} \mathrm{O}_{3}$ particles with a size range of 26-30 nm are still firmly attached to the carbon sheets and Si NPs are 
also dispersed uniformly between $\mathrm{C} @ \mathrm{Fe}_{2} \mathrm{O}_{3}$. This unique structure helps to prevent $\alpha-\mathrm{Fe}_{2} \mathrm{O}_{3}$ and $\mathrm{Si}$ NPs from agglomeration and enables a good dispersion of these active particles over the carbon sheets support. Besides, very thin carbon coating layers can be seen on the surface of Si NPs. The mechanism for the formation of this structure can be explained to be as following. The iron-oleate complex was first synthesized during the aging period and then uniformly mixed with Si NPs. Upon heating under inert atmosphere, the metal-oleate complex was converted to form the two-dimensional hematite/carbon hybrid nanosheet structure, and thin carbon coated Si NPs were sandwiched between these hybrid nanosheets. ${ }^{34-35}$
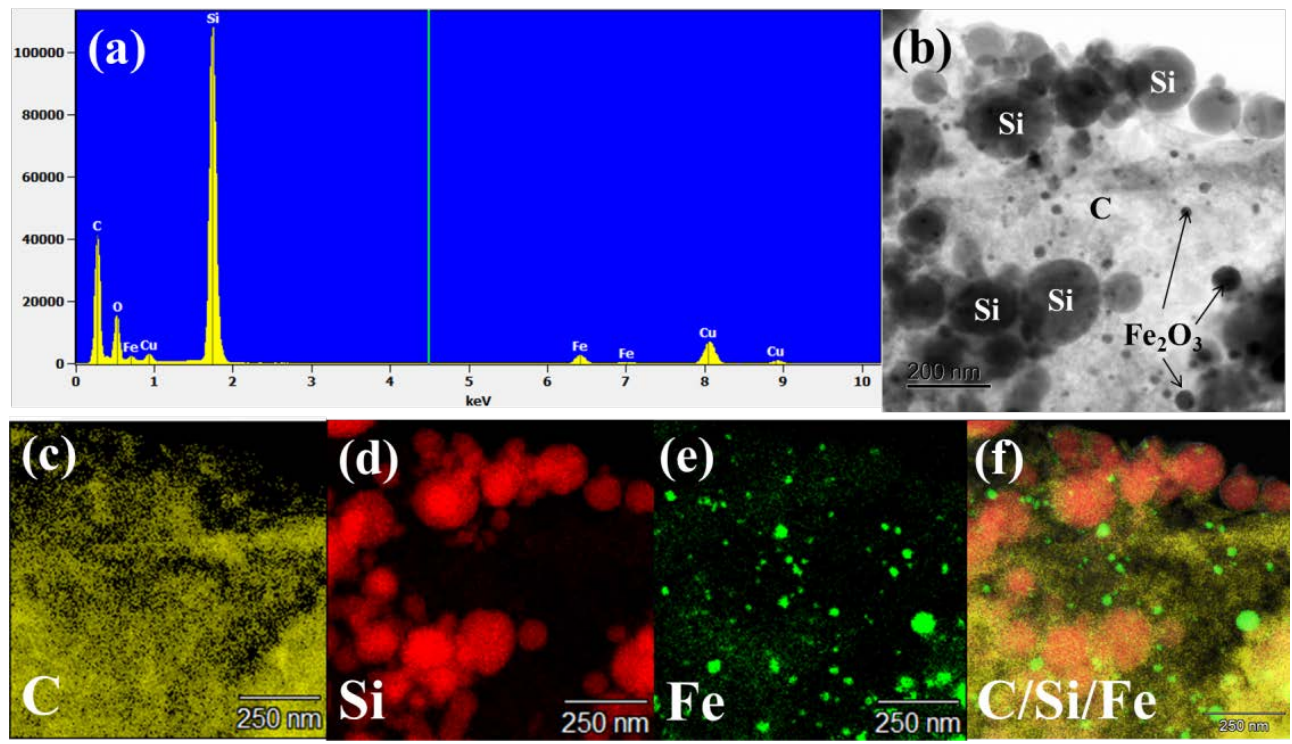

Fig. 2. C-Si-Fe $\mathrm{O}_{3}$ : EDX (a), TEM (b), carbon (yellow), silicon (red) and iron (green) elemental mapping images (c, d, e and f).

Fig. 3a shows the XRD patterns of C-Si-Fe $\mathrm{O}_{3}, \mathrm{C}-\mathrm{Si}$ and Si NPs. For all the samples, there are three distinct diffraction peaks at $2 \theta$ values of $28.3,47.0$, and $55.8^{\circ}$, which can be assigned to (111), (220), and (311) planes of silicon phase (JCPDS NO. 27-1402) respectively. ${ }^{16}$ Besides the silicon phase, in the sample C-Si- $\mathrm{Fe}_{2} \mathrm{O}_{3}$, all the peaks at about 24.1, 33.1, 35.6, 43.3, 49.5, 54.1, 57.5, 62.3, and $65.3^{\circ}$ can be assigned to lattice planes (012), (104), (110), (202), (024), (116), (018), (214), and 
(300), respectively, of $\alpha-\mathrm{Fe}_{2} \mathrm{O}_{3}$ (JCPDS No. 33-0664). ${ }^{28}$

Fig. 3b shows their Raman spectra. For all the silicon-based samples, the strong peaks at about $500 \mathrm{~cm}^{-1}$, are ascribed to $\mathrm{Si}$ and $\mathrm{SiO} .{ }^{36-37}$ The peak at around $1350 \mathrm{~cm}^{-1}$ (D-band) are associated with the vibration of carbon atoms with dangling bonds in plane terminations of the $\mathrm{AC}{ }^{38}$ while the strong peak at about $1590.0 \mathrm{~cm}^{-1}$ (G-band) can be assigned to the vibration of $\mathrm{sp}^{2}$-bonded carbon atoms in a two-dimensional hexagonal lattice, ${ }^{39}$ namely the stretching modes of $\mathrm{C}=\mathrm{C}$ bonds in typical graphite. For the carbon-based samples, a low-intensity and weak G-band peak suggest a structural imperfection of the graphene sheets such as small crystal domain size or defects. ${ }^{40-42}$ Therefore, the carbon inside C-Si- $\mathrm{Fe}_{2} \mathrm{O}_{3}$ and C-Si belongs to AC and has a low graphitization degree. Compared with Si NPs, it can be seen that the peaks around 292 and $606 \mathrm{~cm}^{-1}$ of C-Si-Fe $\mathrm{O}_{3}$ are having better intensity. This increased intensity is due to the overlap of peaks of $\alpha-\mathrm{Fe}_{2} \mathrm{O}_{3}$ and silicon at these positions, indicating the existence of $\alpha-\mathrm{Fe}_{2} \mathrm{O}_{3}$. In agreement with the XRD results, this indicates that the C-Si- $\mathrm{Fe}_{2} \mathrm{O}_{3}$ composite was successfully synthesized via the facial one-step method.

The components of C-Si- $\mathrm{Fe}_{2} \mathrm{O}_{3}$ were further confirmed by X-ray photoelectron spectra (XPS) spectrum, suggesting the presence of $\mathrm{Si}, \mathrm{C}, \mathrm{O}$, and Fe elements in the sample (see Fig. 3c). A high resolution spectrum of Fe 2p is displayed in figure 3d, showing two peaks at about 712.0 and 725.0 $\mathrm{eV}$, corresponding to $\mathrm{Fe} 2 \mathrm{p}_{3 / 2}$ and $\mathrm{Fe} 2 \mathrm{p}_{1 / 2}{ }^{43}$ The carbon content of C-Si- $\mathrm{Fe}_{2} \mathrm{O}_{3}$ was measured using a carbon-hydrogen-nitrogen (CHN) analyzer. 15 wt.\% of carbon was found in C-Si-Fe $\mathrm{O}_{3}$. Based on the ratio of $\mathrm{FeCl}_{3} \cdot 6 \mathrm{H}_{2} \mathrm{O}$ and $\mathrm{Si} \mathrm{NPs}$, the $\alpha-\mathrm{Fe}_{2} \mathrm{O}_{3}$ and silicon content of C-Si-Fe $\mathrm{O}_{3}$ was calculated to be around 20 and $65 \mathrm{wt} \%$, respectively. 

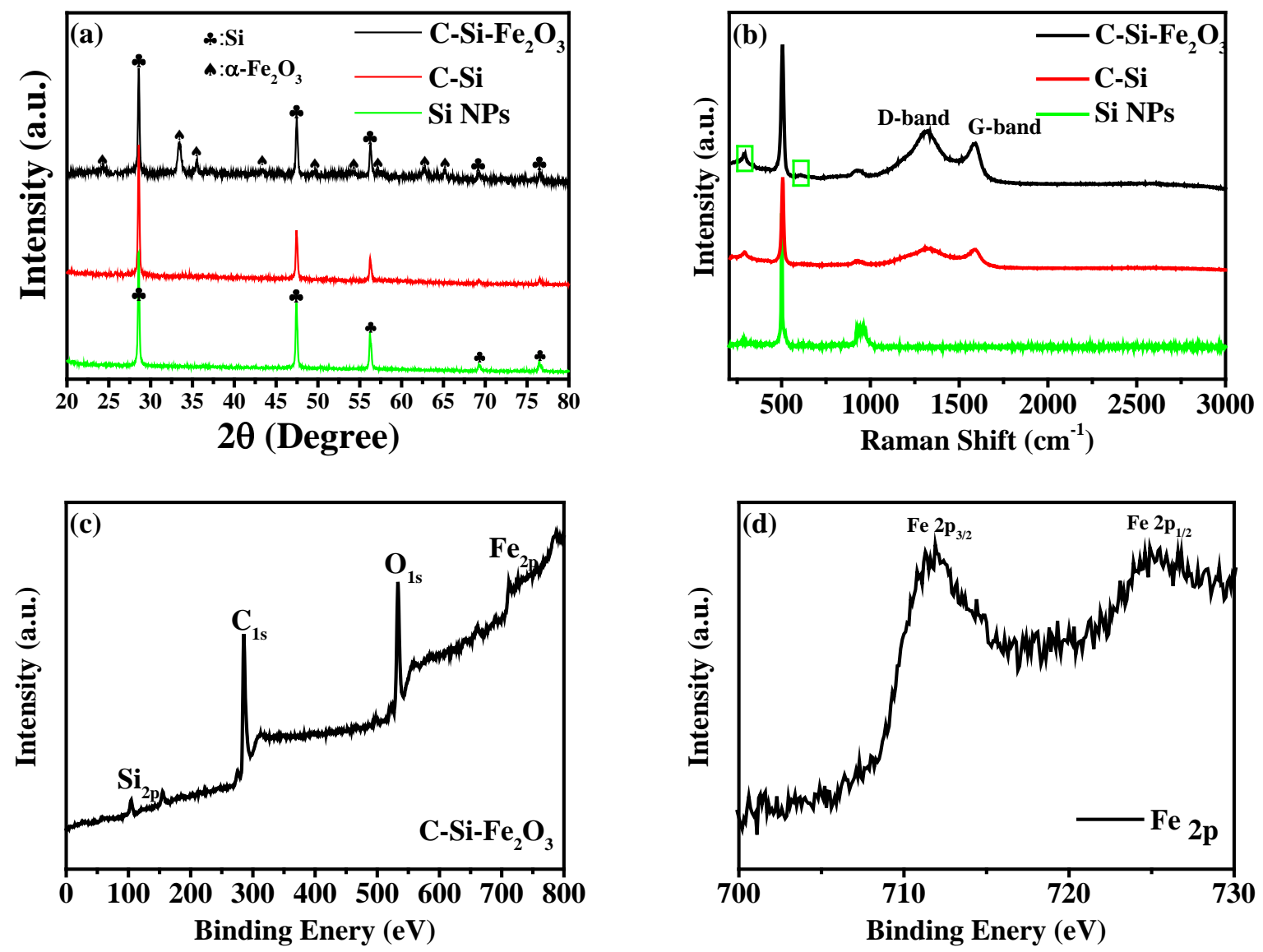

Fig. 3. XRD patterns (a), Raman spectra (b) of all the samples, the wide XPS spectrum of $\mathrm{C}-\mathrm{Si}-\mathrm{Fe}_{2} \mathrm{O}_{3}$ (c) and the high resolution XPS spectrum of Fe 2p (d).

Fig. 4a shows the charge/discharge curves of C-Si-Fe $\mathrm{O}_{3}$ and C-Si at a current density of $750 \mathrm{~mA}$ $\mathrm{g}^{-1}$. The discharge and charge capacities in the first run are about 2846.5 and $1911.4 \mathrm{mAh} \mathrm{g}^{-1}$ for C-Si- $\mathrm{Fe}_{2} \mathrm{O}_{3}$, and 3404.3 and $2206.9 \mathrm{mAh} \mathrm{g}^{-1}$ for C-Si, thus their initial coulombic efficiency is 67.2 and $64.8 \%$, respectively. The low initial coulombic efficiency of the synthesized C-Si-Fe $\mathrm{O}_{3}$ may be because of the secondary reactions such as electrolyte decomposition between electrode and electrolyte that often results in a high irreversibility (low columbic efficiency). ${ }^{44-46}$

Fig. 4b gives the representative first three consecutive cyclic voltammetry (CV) curves of $\mathrm{C}-\mathrm{Si}-\mathrm{Fe}_{2} \mathrm{O}_{3}$ in the voltage range of $0.01-2.8 \mathrm{~V}$ at a scan rate of $0.1 \mathrm{mV} \mathrm{s}^{-1}$. During the first discharge process, two reduction peaks at 1.48 and $0.68 \mathrm{~V}$ can be observed, which could be related 
to a multi-step electrochemical reduction process. ${ }^{6,47-48}$ Specifically, the small cathodic peak at 1.48 $\mathrm{V}$ can be respectively ascribed to the initial lithium intercalation and the phase transition from hexagonal $\mathrm{Li}_{\mathrm{x}}\left(\mathrm{Fe}_{2} \mathrm{O}_{3}\right)$ to cubic $\mathrm{Li}_{2}\left(\mathrm{Fe}_{2} \mathrm{O}_{3}\right) .{ }^{49-50}$ Besides, another cathodic peak located around 0.68 $\mathrm{V}$, which disappears from the second cycle, can be attributed to the further reduction of the $\mathrm{Li}_{2}\left(\mathrm{Fe}_{2} \mathrm{O}_{3}\right)$ into $\mathrm{Fe}^{0}$, as well as the formation of SEI layer. ${ }^{51}$ Thus, the reactions are speculated to be as following formulas.

$$
\begin{aligned}
& \mathrm{Fe}_{2} \mathrm{O}_{3}+2 \mathrm{Li}^{+}+2 \mathrm{e}^{-} \rightarrow \mathrm{Li}_{2}\left(\mathrm{Fe}_{2} \mathrm{O}_{3}\right) \\
& \mathrm{Li}_{2}\left(\mathrm{Fe}_{2} \mathrm{O}_{3}\right)+4 \mathrm{Li}^{+}+4 \mathrm{e}^{-} \rightarrow 2 \mathrm{Fe}^{0}+3 \mathrm{Li}_{2} \mathrm{O}
\end{aligned}
$$

In addition, another cathodic at $0.18 \mathrm{~V}$ appears since the second cycle, attributed to the alloying of lithium with silicon. ${ }^{52}$ The subsequent broad anodic peaks during the charge process are observed at 1.60 and $1.93 \mathrm{~V}$, indicating the multiple step oxidation of $\mathrm{Fe}^{0} \cdot{ }^{26,49,53}$ Meanwhile, the other oxidative peaks located at about 0.31 and $0.48 \mathrm{~V}$ are due to the extraction of lithium ions from the carbon and dealloying of $\mathrm{Li}_{\mathrm{x}} \mathrm{Si}^{7,30}$ The general overlapping of charge curves implies the good reversibility and stability of the electrochemical reaction. ${ }^{6}$ These results nearly coincide with the voltage plateaus in the galvanostatic discharge-charge curve (Fig. 4a) and consistent with its good cycling performance as discussed below. However, compared with C-Si-Fe $\mathrm{O}_{3}$, the first three CV curves of C-Si in Fig. S3 are quite different. Only the reduction peaks below $0.3 \mathrm{~V}$ and anodic peaks around $0.5 \mathrm{~V}$ can be found.

The cycling performance in Fig. 4c shows the charge/discharge capacity of $\mathrm{C}-\mathrm{Si}-\mathrm{Fe}_{2} \mathrm{O}_{3}$ at a current density of $750 \mathrm{~mA} \mathrm{~g}^{-1}$ for 200 cycles. It can be seen, the charge capacity is $1911.4 \mathrm{mAh} \mathrm{g}^{-1}$ at the first cycle and $2015.4 \mathrm{mAh} \mathrm{g}^{-1}$ after 200 cycles, suggesting that $\mathrm{C}-\mathrm{Si}-\mathrm{Fe}_{2} \mathrm{O}_{3}$ has a high capacity and good cycling stability. Meanwhile, a small decrease of reversible capacity is observed during the first 50 cycles. After that, the capacity starts to increase slowly and reaches the plateau 
after the 100 cycle. It is known that the capacity of AC is around $600.0 \mathrm{mAh} \mathrm{g}^{-1}{ }^{54}$ Thus, the improved capacity for $\mathrm{C}-\mathrm{Si}-\mathrm{Fe}_{2} \mathrm{O}_{3}$ is attributed to the contribution of silicon and $\alpha-\mathrm{Fe}_{2} \mathrm{O}_{3}$ nanoparticles, and the capacity of silicon, $\alpha-\mathrm{Fe}_{2} \mathrm{O}_{3}$ and AC is calculated to be around 2730.0, 200.0 and $90.0 \mathrm{mAh} \mathrm{g}^{-1}$ (based on the CHN data). Therefore, the theoretical capacity of C-Si- $\mathrm{Fe}_{2} \mathrm{O}_{3}$ is around $3020.0 \mathrm{mAh} \mathrm{g}^{-1}$ and the capacity retention is about $66.7 \%$ even after 200 cycles.

Fig. 4d shows the rate performance of samples at different current densities. The charge capacities of C-Si-Fe $\mathrm{O}_{3}$ and C-Si at the first $0.75 \mathrm{~A} \mathrm{~g}^{-1}$ after 20 cycles are 1472.0 and $1148.3 \mathrm{mAh}$ $\mathrm{g}^{-1}$, respectively, and the retention of the capacity at $1.5,3.0$, and $6.0 \mathrm{~A} \mathrm{~g}^{-1}$ is $96.2,66.0$, and $50.4 \%$ for $\mathrm{C}-\mathrm{Si}-\mathrm{Fe}_{2} \mathrm{O}_{3}$, higher than those of the C-Si $(61.2,12.8$, and 5.8\%), especially at the current densities of 3.0 and $6.0 \mathrm{~A} \mathrm{~g}^{-1}$, indicating the better rate performance of C-Si- $\mathrm{Fe}_{2} \mathrm{O}_{3}$. More importantly, compared with C-Si, after the high rate charge and discharge, a much higher reversible capacity of $\mathrm{C}-\mathrm{Si}-\mathrm{Fe}_{2} \mathrm{O}_{3}$ can still be maintained for the next 150 cycles. Fig. S4 shows the electrochemical impedance plots of $\mathrm{C}-\mathrm{Si}-\mathrm{Fe}_{2} \mathrm{O}_{3}$ and C-Si. It can be seen, the solution resistance of C-Si- $\mathrm{Fe}_{2} \mathrm{O}_{3}$ is less than C-Si, suggesting that $\mathrm{C}-\mathrm{Si}-\mathrm{Fe}_{2} \mathrm{O}_{3}$ has a better electronic conductivity and rate performance. $^{7}$

The enhanced electrochemical properties of the porous $\mathrm{C}-\mathrm{Si}-\mathrm{Fe}_{2} \mathrm{O}_{3}$ could be attributed to its unique architecture: (1) the sandwich nanoarchitecture helps to prevent $\alpha-\mathrm{Fe}_{2} \mathrm{O}_{3}$ and Si NPs from agglomeration and enables a good dispersion of these active particles over the carbon sheets support; (2) multilayered structure can form a porous, highly conducting 3D network that can serve as a structural scaffold to improve the electronic conductivity, strengthen the mechanical properties and also provides better room for the huge volume change of Si NPs and $\alpha-\mathrm{Fe}_{2} \mathrm{O}_{3}$ during cycling; ${ }^{5,55-56}$ and (3) nano-sized $\alpha-\mathrm{Fe}_{2} \mathrm{O}_{3}$ particles $(\approx 30 \mathrm{~nm}$ ) uniformly embedded on the carbon layers will enhance the diffusion process, which leads to the less tortuosity of electrode and higher electrolyte 
diffusion thus enhancing the rate performance. ${ }^{57}$
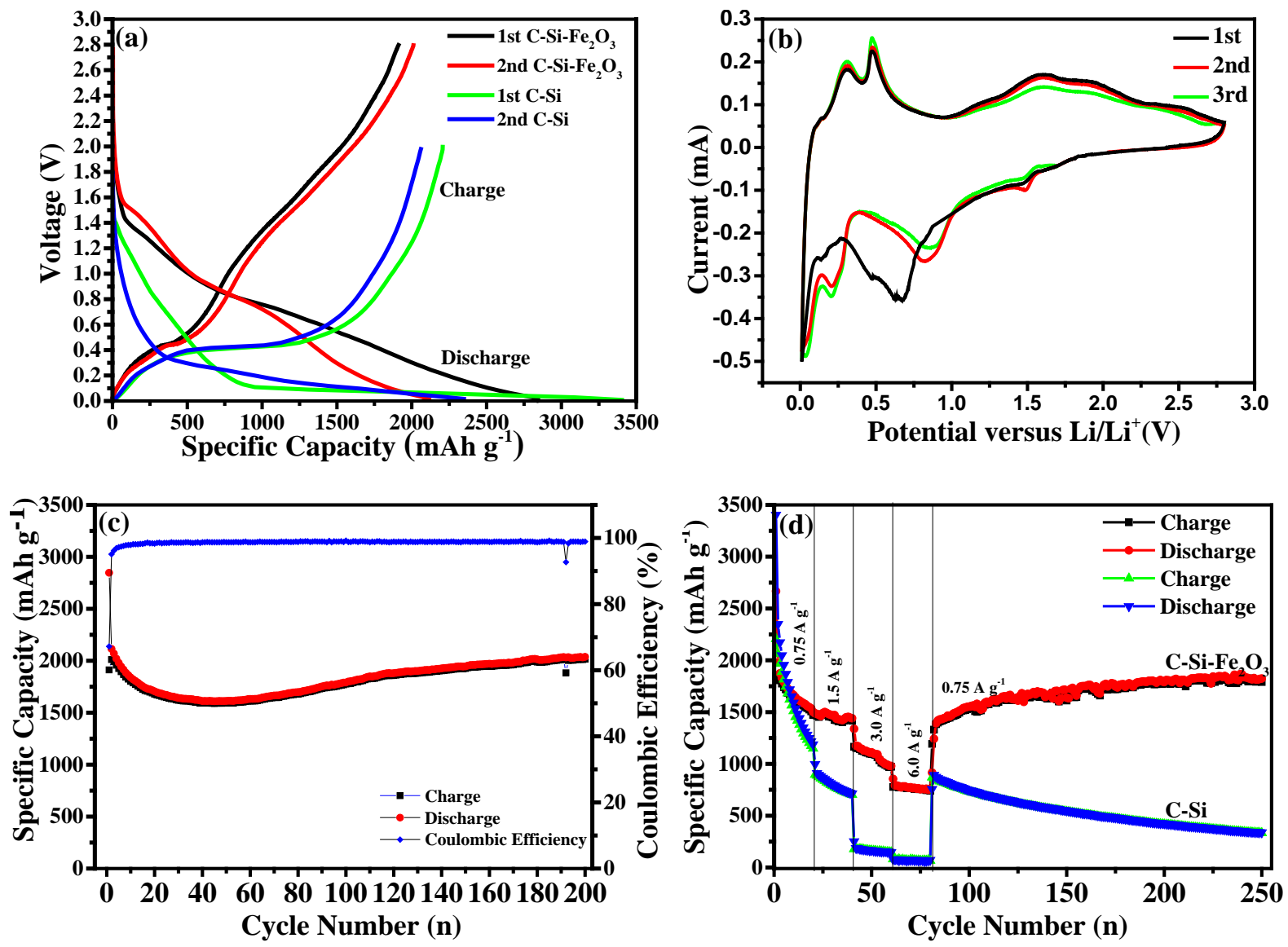

Fig. 4. Electrochemical properties: (a) the initial discharge-charge of $\mathrm{C}-\mathrm{Si}-\mathrm{Fe}_{2} \mathrm{O}_{3}$ and $\mathrm{C}-\mathrm{Si}$, (b) the first three consecutive $\mathrm{CV}$ curves of $\mathrm{C}-\mathrm{Si}-\mathrm{Fe}_{2} \mathrm{O}_{3}$ at a scan rate $0.1 \mathrm{mV} \mathrm{s}^{-1}$, (c) cycling property for C-Si- $\mathrm{Fe}_{2} \mathrm{O}_{3}$ between 2.8 and $0.01 \mathrm{~V}$ at the current density of $750 \mathrm{~mA} \mathrm{~g}^{-1}$, and (d) the rate performance of C-Si-Fe $\mathrm{O}_{3}$ and $\mathrm{C}-\mathrm{Si}$ at different current densities.

\section{Conclusions}

In summary, we have demonstrated a facile and scalable method for preparing a novel nanoarchitecture of carbon@silicon@hematite (C-Si- $\left.\mathrm{Fe}_{2} \mathrm{O}_{3}\right)$ composite employing the one-step self-assembled method. Silicon nanoparticles sandwiched between the nanosized iron oxide embedded carbon layers, and more importantly, portions of these carbon sheets stacked reconstitute to form a porous conductive network. Rationally designed unique 3D porous carbon network 
enhances the electrical conductivity and enables this $\mathrm{C}-\mathrm{Si}-\mathrm{Fe}_{2} \mathrm{O}_{3}$ composite to buffer the volume change of silicon and $\alpha-\mathrm{Fe}_{2} \mathrm{O}_{3}$ during the cycling much more effectively. Compared with the commercial graphite microspheres (372 $\mathrm{mAh} \mathrm{g}^{-1}$ ), C-Si- $\mathrm{Fe}_{2} \mathrm{O}_{3}$ shows much higher capacity and better rate performance. Clearly, the simplicity and scalability of this fabrication process and the excellent electrochemical property will make C-Si-Fe $\mathrm{O}_{3}$ anode material promising for the practical application in the next generation Li-ion cells.

\section{Acknowledgements}

This work is supported by a BAJC (Baosteel-Australia Joint Research \& Development Centre) project BA14006 and an Auto CRC 2020, Project 1-117. Lei Zhang would like to thank CSC scholarships from China. The authors would like to also thank Dr. Tania Silver for critical reading of the manuscript and Dr. Dongqi Shi for XPS testing and also acknowledge the use of the facilities in the UOW Electron Microscopy Center, with particular thanks to Dr. Gilberto Casillas-Garcia.

\section{References}

1. J. B. Goodenough and Y. Kim, Chem. Mater., 2010, 22,587-603.

2. B. Dunn, H. Kamath and J. M. Tarascon, Science, 2011, 334,928-35.

3. M. Armand and J.-M. Tarascon, Nature, 2008, 451,652-657.

4. M. S. Whittingham, Chem. Rev, 2004, 104,4271-4301.

5. $\quad$ N. Liu, H. Wu, M. T. McDowell, Y. Yao, C. Wang and Y. Cui, Nano Lett., 2012, 12,3315-3321.

6. L. Li, H. B. Wu, L. Yu, S. Madhavi and X. W. D. Lou, Adv. Mater. Interface, 2014, 1,1400050.

7. L. Zhang, Y. Wang, G. Kan, Z. Zhang, C. Wang, Z. Zhong and F. Su, RSC Adv., 2014, 4,43114-43120.

8. N. Liu, Z. Lu, J. Zhao, M. T. McDowell, H. W. Lee, W. Zhao and Y. Cui, Nat. Nanotechnol., 2014, 9,187-92.

9. Y. Z. Xianjun Zhu, Shanthi Murali, Meryl D. Stoller, and Rodney S. Ruoff,, ACS Nano, 2011, 5,3333-3338.

10. A. M. Chockla, J. T. Harris, V. A. Akhavan, T. D. Bogart, V. C. Holmberg, C. Steinhagen, C. B. Mullins, K. J. Stevenson and B. A. Korgel, J. Am. Chem. Soc., 2011, 133,20914-20921.

11. X. Zhou, Y.-X. Yin, A.-M. Cao, L.-J. Wan and Y.-G. Guo, ACS Appl. Mater. Interfaces, 2012, 4,2824-2828.

12. H. Jia, P. Gao, J. Yang, J. Wang, Y. Nuli and Z. Yang, Adv. Energy Mater., 2011, 1,1036-1039.

13. B. Liu, X. Wang, H. Chen, Z. Wang, D. Chen, Y. B. Cheng, C. Zhou and G. Shen, Sci. Rep., 2013, 3,1622. 
14. B. Z. Igor Kovalenko, Alexandre Magasinski, Benjamin Hertzberg, Zoran Milicev, Ruslan Burtovyy, Igor Luzinov, Gleb Yushin, Science, 2011, 334,75-79.

15. P. Y. C. Wu, X. Zhu, C. Yang, and Y. Xie, J. Phys. Chem. B, 2006, 110,17806-17812.

16. J. Yu, H. H. Zhan, Y. H. Wang, Z. L. I. Zhang, H. Chen, H. Li, Z. Y. Zhong and F. B. Su, J. Power Sources, 2013, 228,112-119.

17. P. Gu, R. Cai, Y. Zhou and Z. Shao, Electrochim. Acta, 2010, 55,3876-3883.

18. W. Wang and P. N. Kumta, ACS nano, 2010, 4,2233-2241.

19. X. H. Liu, L. Zhong, S. Huang, S. X. Mao, T. Zhu and J. Y. Huang, Acs Nano, 2012, 6,1522-1531.

20. A. Kohandehghan, P. Kalisvaart, K. Cui, M. Kupsta, E. Memarzadeh and D. Mitlin, J. Mater. Chem. A, 2013,

21. M. Ge, J. Rong, X. Fang and C. Zhou, Nano Lett., 2012, 12,2318-2323.

22. T. Song, J. Xia, J. H. Lee, D. H. Lee, M. S. Kwon, J. M. Choi, J. Wu, S. K. Doo, H. Chang, W. I. Park, D. S. Zang, H. Kim, Y. Huang, K. C. Hwang, J. A. Rogers and U. Paik, Nano Lett., 2010, 10,1710-1716.

23. M. Y. Ge, J. P. Rong, X. Fang, A. Y. Zhang, Y. H. Lu and C. W. Zhou, Nano Res., 2013, 6,174-181.

24. J. H. Kong, W. A. Yee, Y. F. Wei, L. P. Yang, J. M. Ang, S. L. Phua, S. Y. Wong, R. Zhou, Y. L. Dong, X. Li and X. H. Lu, Nanoscale, 2013, 5,2967-2973.

25. R. C. de Guzman, J. H. Yang, M. Ming-Cheng, S. O. Salley and K. Y. S. Ng, Asian J. Mater. Sci., 2013, 48,4823-4833.

26. L. X. Jun Chen, Weiyang Li, and Xinglong Gou, Adv. Mater., 2005, 17,582-586.

27. H. W. Nian Liu, Matthew T. McDowell, Yan Yao, Chongmin Wang, and Yi Cui, Nano Lett., 2012, 12,3315-3321.

28. Z.-J. Zhang, Y.-X. Wang, S.-L. Chou, H.-J. Li, H.-K. Liu and J.-Z. Wang, J. Power Sources, 2015, 280,107-113.

29. J. K. Lee, K. B. Smith, C. M. Hayner and H. H. Kung, Chem. Commun., 2010, 46,2025-7.

30. X. L. Bin Wang, Xianfeng Zhang, Bin Luo, Meihua Jin, Minghui Liang, Shadi A. Dayeh, S. T. Picraux, and Linjie Zhi, ACS nano, 2013, 7,1437-1445.

31. J. Z. Xianghong Liu, Wenping Si, Lixia Xi, Barbara Eichler, Chenglin Yan, and Oliver G. Schmidt, ACS nano, 2015, 9,1198-1205.

32. J. Chang, X. Huang, G. Zhou, S. Cui, P. B. Hallac, J. Jiang, P. T. Hurley and J. Chen, Adv Mater, 2014, 26,758-64.

33. L. Chen, Z. Wang, C. He, N. Zhao, C. Shi, E.-Z. Liu and J. Li, ACS Appl. Mater. Interfaces, 2013, 5,9537-9545.

34. B. Jang, M. Park, O. B. Chae, S. Park, Y. Kim, S. M. Oh, Y. Piao and T. Hyeon, J. Am. Chem. Soc., 2012, 134,15010-5.

35. J. Park, K. An, Y. Hwang, J. G. Park, H. J. Noh, J. Y. Kim, J. H. Park, N. M. Hwang and T. Hyeon, Nat. Mater., 2004, 3,891-895.

36. X. Zhu, H. Chen, Y. Wang, L. Xia, Q. Tan, H. Li, Z. Zhong, F. Su and X. Zhao, J. Mater. Chem. A, 2013, 1,4483-4489.

37. J. I. Lee, K. T. Lee, J. Cho, J. Kim, N. S. Choi and S. Park, Angew. Chem., 2012, 124,2821-2825.

38. S. Ray, C. Pao, H. Tsai, B. Bose, J. Chiou, W. Pong and D. DasGupta, Carbon, 2006, 44,1982-1985.

39. L. Ji and X. Zhang, Carbon, 2009, 47,3219-3226.

40. F. Su, X. Zhao, Y. Wang, J. Zeng, Z. Zhou and J. Y. Lee, J. Phys. Chem. B, 2005, 109,20200-20206.

41. A. Cuesta, P. Dhamelincourt, J. Laureyns, A. Martinez-Alonso and J. M. Tascón, J. Mater. Chem., 1998, 8,2875-2879.

42. Q. Yang, W. Xu, A. Tomita and T. Kyotani, J. Am. Chem. Soc., 2005, 127,8956-8957.

43. J. Zhang, X. Liu, L. Wang, T. Yang, X. Guo, S. Wu, S. Wang and S. Zhang, Nanotechnology, 2011, $22,185501$.

44. Y. G. Guo, J. S. Hu and L. J. Wan, Adv. Mater., 2008, 20,2878-2887.

45. A. Mabuchi, K. Tokumitsu, H. Fujimoto and T. Kasuh, J. Electrochem. Soc., 1995, 142,1041-1046.

46. Y. Liu, J. Xue, T. Zheng and J. Dahn, Carbon, 1996, 34,193-200.

47. C. T. Cherian, J. Sundaramurthy, M. Kalaivani, P. Ragupathy, P. S. Kumar, V. Thavasi, M. V. Reddy, C. H. Sow, S. G. Mhaisalkar, S. Ramakrishna and B. V. R. Chowdari, J. Mater. Chem., 2012, 22,12198-12204. 
48. D. Larcher, D. Bonnin, R. Cortes, I. Rivals, L. Personnaz and J. M. Tarascon, J. Electrochem. Soc., 2003, 150,A1643-A1650.

49. J. Luo, X. Xia, Y. Luo, C. Guan, J. Liu, X. Qi, C. F. Ng, T. Yu, H. Zhang and H. J. Fan, Adv. Energy Mater., 2013, 3,737-743.

50. S.-L. Chou, J.-Z. Wang, D. Wexler, K. Konstantinov, C. Zhong, H.-K. Liu and S.-X. Dou, J. Mater. Chem., 2010, 20,2092-2098.

51. Y. Luo, D. Kong, J. Luo, Y. Wang, D. Zhang, K. Qiu, C. Cheng, C. M. Li and T. Yu, RSC Adv., 2014, 4,13241-13249.

52. Y.-X. Wang, S.-L. Chou, J. H. Kim, H.-K. Liu and S.-X. Dou, Electrochim. Acta, 2013, 93,213-221.

53. D. Larcher, C. Masquelier, D. Bonnin, Y. Chabre, V. Masson, J. B. Leriche and J. M. Tarascon, J. Electrochem. Soc., 2003, 150,A133-A139.

54. L. Zhang, M. Zhang, Y. Wang, Z. Zhang, G. Kan, C. Wang, Z. Zhong and F. Su, J. Mater. Chem. A, 2014, 2,10161-10168.

55. A. Vu, Y. Qian and A. Stein, Adv. Energy Mater., 2012, 2,1056-1085.

56. T. Cetinkaya, M. Uysal, M. O. Guler, H. Akbulut and A. Alp, Powder Technol., 2014, 253,63-69.

57. M. Ebner, D.-W. Chung, R. E. García and V. Wood, Adv. Energy Mater., 2014, 4,1301278. 